\title{
Linking with uncertainty: The relationship between EU ETS pollution permits and Kyoto offsets
}

\author{
Beat Hintermann* \\ Marc Gronwald ${ }^{\dagger}$
}

May 22, 2019

\begin{abstract}
Carbon offsets from the Kyoto Flexible Mechanisms can be used by firms in the EU Emissions Trading Scheme for compliance in lieu of EU allowances, making these carbon assets interchangeable. We offer an explanation of the price spread using a structural model of the price for Certified Emissions Reductions that combines three features: A limit for the use of Kyoto offsets within the EU ETS; a disconnect between the current price of offsets and their marginal cost of production due to institutional reasons; and uncertainty about future supply and demand of offsets. Our model expresses the offset price as an average of the EU allowance price and an offset's outside value, weighted by the probability of a binding import limit. Using monthly series of the United Nation's Clean Development Mechanism and Joint Implementation about offset supply and demand, we provide empirical support for our theory of offset price formation. Counterfactual simulations suggest that the price process is dominated by uncertainty.
\end{abstract}

*University of Basel and CESifo. Address: University of Basel, Department of Economics, Peter Merian-Weg 6, Basel, Switzerland; b.hintermann@unibas.ch.

†University of Aberdeen, CESifo and ifo Institute for Economic Research. Address: University of Aberdeen Business School, Edward Wright Building Block B, Dunbar Street, Aberdeen, AB24 3QY, United Kingdom; phone: +44 1224 272204; email: mgronwald@abdn.ac.uk. 


\section{Introduction}

In order to reduce the European Union's cost to comply with the Kyoto Protocol, the European Commission allowed firms included in the European Union Emissions Trading Scheme (EU ETS) to cover a part of their $\mathrm{CO}_{2}$ emissions using offsets from the Kyoto flexible mechanisms. This established a link between the EU ETS and the Kyoto markets The two types of emission certificates were interchangeable assets in principle, because both provide the holder with the right to emit one ton of $\mathrm{CO}_{2}$. Not surprisingly, the price for EU allowances (EUAs) on the one hand, and Certified Emission Reductions (CERs) and Emission Reduction Units (ERUs) on the other, have been highly correlated during the Kyoto period and beyond. $2^{2}$

However, the price for EUAs has consistently been higher than the price for CERs. Figure 1 shows the corresponding price histories.

Figure 1: Prices for EUAs, CERs (left axis) and their spread (right axis)

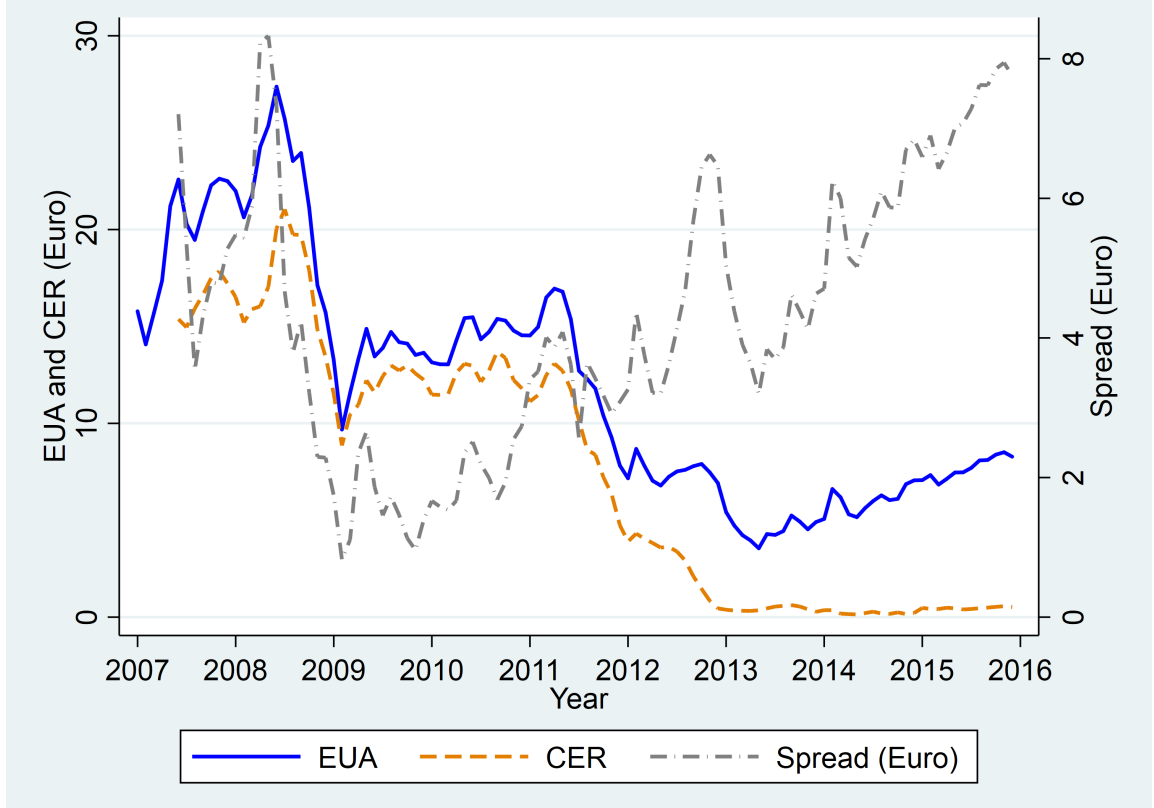

Source: Own illustration based on data from Thomson Reuters Datastream.

Some explanations for the price spread have been proposed in the literature: Some authors have focused on transactions costs (Trotignon, 2012; Braun et al., 2015), whereas others argue that the two carbon assets react differently to fundamentals such as fuel prices and economic activity (e.g.,

\footnotetext{
${ }^{1}$ This article contains a number of acronyms. To aid the reader, a table of relevant acronyms can be found in the appendix.

${ }^{2}$ Because prices for CERs and ERUs are practically identical, but the liquidity of the former far exceeded that of the latter before 2012, we use the CER price throughout the paper. In our empirical analysis, we focus on secondary CERs throughout the paper, which do not contain delivery risk.
} 
Nazifi, 2013; Mansanet-Bataller et al., 2011). However, transactions costs would presumably drive a (roughly) constant wedge between prices, and establishing a difference in the sensitivity to price fundamentals neither explain the source of this difference nor why it persists. Furthermore, if the markets were fully independent and each carbon asset driven by the (marginal) cost to generate it, we would not expect the high degree of correlation that has been observed, given that abatement cost curves are unlikely to be the same in Western Europe and in developing countries. Previous authors have noted the importance of the import limit and of the expected demand and supply for offsets for CER prices (see, e.g., Chevallier, 2011; Mansanet-Bataller et al., 2011; Nazifi, 2013). However, these studies limit the analysis to standard time-series techniques and do not provide a structural or economic explanation of the price spread.

In this paper, we explain the the EUA-CER price spread by proposing a specific economic mechanism that links these two prices, and which depends on the import limit and the expected future supply and demand of offsets. The underlying assumption is that due to the lengthy and complicated process underlying the generation and verification, the current expected supply of CERs is independent of its current price. Our model is the first to (i) explicitly incorporate uncertainty about the net position of the offset market into a CER pricing equation and (ii) include data about offset demand and supply in our empirical analysis. We derive an pricing model that allows for a dynamic relationship between the two carbon assets, which changes as new information becomes available. We propose uncertainty about future offset supply and demand, combined with a limitation of the number of offsets that could be used within the EU ETS, as the main price drivers for Kyoto offsets. Our model explains a significant share of the observed price spread, and it is furthermore consistent with the observation that the price for offsets gradually dropped to (near) zero by the end of 2012 .

Without any restrictions, linking two emissions trading schemes leads to a single permit price, equal to the cost of reducing emissions by one ton below the aggregate cap. But since the EU imposed a limit of Kyoto offsets that could maximally be used in the EU ETS during Phase II, the prices for EUAs and offsets need not converge $]^{3}$ In general, a binding transfer limit breaks the link between two emission permit markets. Once the allowable number of permits has been transferred from the cheaper to the more expensive system, the situation is identical to one where two separate permit

\footnotetext{
${ }^{3}$ Throughout this paper, the term "phase" refers to the different market phases of the EU ETS: Phase I (2005-2007), Phase II (2008-2012), and Phase III (2012-2020). For a more extensive discussion of the design of the EU ETS, see Hintermann and Gronwald (2015) and Ellerman et al. (2016). No explicit such phases exist in the market for CERs. A review of the literature focusing on the drivers of EUA prices is given by Hintermann et al. (2016).
} 
markets coexist, but where some of the cap has been transferred from one market to the other. ${ }^{4}$

This reasoning abstracts from uncertainty. During much of Phase II, it was not clear whether the import limit for offsets would turn out to be binding due to uncertainty on both the supply and the demand side. Generating emission offsets either via the Clean Development Mechanism (CDM) or by Joint Implementation (JI) is a complicated and lengthy procedure (Trotignon and Leguet, 2009). Between the original proposal and the delivery of verified offsets, a project has to clear a number of administrative stages, at each of which it may be rejected, delayed or its projected generation of offsets adjusted. From market participants' point of view, the total supply of offsets by a certain date is therefore uncertain. The demand for offsets was uncertain as well, as it depended (besides demand from ETS firms) on the extent to which Annex B countries of the Kyoto Protocol needed to rely on offsets to achieve their emission reduction goals. 5

We derive a model that expresses the offset price as an average of the EUA price and an offset's outside value, weighted by the probability that the import limit turns out to be binding. The identifying assumption of our model is that due to the lengthy process that underlies the generation of Kyoto offsets, the current number of expected offsets is independent of the current offset price. We calibrate the free model parameters using data about the expected supply and demand of offsets. The calibrated model explains a significant share of the CER price variation. A supporting cointegration and error correction analysis shows that the cointegration between EUA and CER prices broke down at the same time as the probability of a binding import limit sharply increased. This suggests that our model identifies the principal mechanism underlying the CER price formation.

\section{Background}

In the following, we present background information about the Kyoto flexible mechanisms and the EU's "Linking Directive" that established a link with the EU ETS, and present a short review of the literature that is concerned with the market for Kyoto offsets.

\footnotetext{
${ }^{4}$ For a more detailed illustration of this point, see Grüll and Taschini (2012).

${ }^{5}$ Annex B countries agreed to binding emission reduction targets under the Kyoto Protocol. Countries' emissions during a calendar year are not made publicly available until the various sources have been checked and verified, which often results in the publication of annual emissions not before the end of the following year. The deadline for purchasing offsets was set by the end of the "true-up period", which was on November 18, 2015; see the United Nations Framework on Climate Change, "True-up period reporting and review process", available at http://unfccc.int/kyoto_Protocol/trueup_process/items/9023.php, last accessed on January 15, 2016.
} 


\subsection{The Kyoto flexible mechanisms}

The Kyoto Protocol's flexible mechanisms were designed to lower the cost of achieving the emissions reductions agreed to by the countries listed in Annex B (i.e., the countries that agreed to binding emissions reductions), by carrying out emissions-reducing projects more cost-effectively in other countries. The Kyoto Protocol differentiates between two types of flexible mechanisms based on where the emissions reductions take place. Projects in developing countries are governed by the Clean Development Mechanism (CDM) and produce one Certified Emissions Reduction (CER) per avoided metric ton of $\mathrm{CO}_{2}$. Emissions reductions in other Annex B countries fall under the flexible mechanism called Joint Implementation (JI), and result in the issuance of an Emissions Reduction Unit (ERU) per metric ton of $\mathrm{CO}_{2}$. CERs and ERUs therefore only differ in terms of their origin, but not in terms of their "content" or the way they can be used, and we therefore refer to both as "Kyoto offsets" or simply offsets. The prices for CERs and ERUs were largely identical, although the market for the former was much more liquid than that of the latter; a graph of the CER and ERU prices is shown in Figure A1 in the appendix. The price convergence is consistent with our model where the price for offsets is determined by their value of their use rather than their marginal cost of production (see below), which likely differs between Annex B and developing countries.

CDM project activities have to comply with the requirements defined by the United Nations Framework Convention on Climate Change (UNFCCC, 2015a). They have to follow a seven-step process, which is illustrated in Figure 2 .

The first step consists in the project participants (i.e., the entity that proposes to carry out the actual project) preparing a project design document (PDD) in accordance with guidelines laid out in UNFCCC (2015b), and submitting it to the Designated National Authorities (DNA) of both countries involved (i.e., the country of the project participant, and the country where the project is to be implemented). The PDD describes the proposed project and lists the expected emissions reduction per year of operation. The preparation of the PDD can be the most time-consuming step in the entire project cycle (UNFCCC, 2013).

If satisfied, the DNAs write a letter of approval confirming that both parties are part of the Kyoto Protocol, and that the project contributes to the host country's sustainable development. Based on this national approval, the project participants then contract an independent auditor, a so-called designated 
Figure 2: CDM project cycle

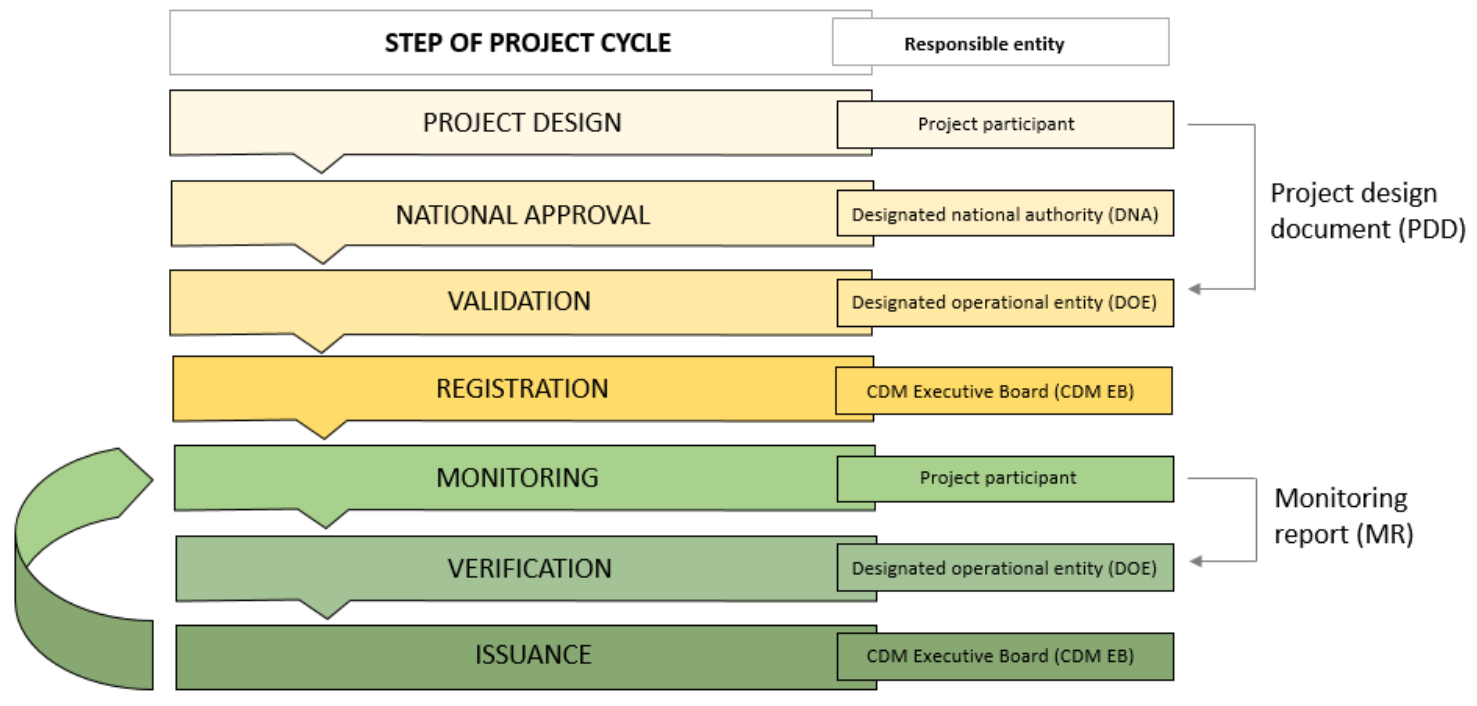

Source: Own illustration based on Fig. 3.1 in UNFCCC (2013).

operational entity (DOE) for the validation of the project activity. project proposal is consistent with the requirements of the CDM according to additionality and other requirements defined in UNFCCC (2015bc), and makes the PDD publicly available for a 30-day consultation period. Based on the comments from the various stakeholders, the DOE either validates (i.e., approves) or rejects the project. If the project has been validated, the DOE submits a request for registration. After an additional check for completeness by the UNFCCC secretariat, the request is made publicly available. If no review request is received within 28 days, the CDM EB registers the proposed project; otherwise, and additional review takes place. All CDM projects must be registered before they can be implemented.

After the implementation of the project, the project participants have to prepare a monitoring report at regular intervals that demonstrates the emission reduction achieved, and submit it to a DOE for verification:7 The DOE verifies whether the reported emission reduction took place, based on the requirements for additionality defined in $\overline{\mathrm{UNFCCC}}(2015 \mathrm{c})$ and an on-site inspection. If the MR has been verified, the DOE submits a request for issuance of CERs to the CDM EB. This request is again made publicly available. If no review request is received from any party involved in the project within 28 days, the CDM EB grants the issuance of CERs according to the number of verified emission reductions. The last three steps are repeated for the duration of the project.

\footnotetext{
${ }^{6}$ Firms or organizations have to be registered by the UNFCCC in order to become DOEs. The Executive Board of the Clean Development Mechanism (CDM EB) maintains a public list of approved DOEs.

${ }^{7}$ The DOE contracted for the verification of the achieved emission reductions usually differs from the DOE contracted for validation, but the same DOE can be contracted upon request.
} 
At each step of the CDM project cycle, a project may be rejected, or approved subject to additional requirements, which may cause a significant delay (Trotignon and Leguet, 2009). Furthermore, the number of CERs produced per year may be smaller or greater than the emissions reductions specified in the original PDD. The United Nations Environment Programme maintains a database of all CDM projects and tracks their progress that have been approved by the DNA; this monthly database is the source for our offset supply data (see below).

The total time between the initial project idea and the eventual delivery of CERs depends on the nature of the project and the involved countries. The average time lag between the comment period (during validation) and the registration of a project is shown in Figure A2 in the appendix, and Figure A3 presents the average time lag between the end of the monitoring period and the issuance of CERs. Figure A4 shows the number of projects at different stages of the CDM cycle. The total time it takes to "create" a CER is the sum of the time lags shown in these figures, plus the time it takes to create the PDD (anywhere between 6 months and several years) and to obtain the letters of recommendation, plus the monitoring period (usually a year), which can easily add up to 5 or more years in total. This implies that the supply of CERs cannot increased in response to an increase in the CER price, at least not in the short to medium run.

The procedures governing Joint Implementation are very similar to those for CDM, with the main difference being that two Annex B countries are involved. More details about the JI are provided in the appendix.

\subsection{The "Linking Directive"}

In the directive that set up the EU ETS, the European Commission allowed the included firms to cover some of their emissions using Kyoto offsets (European Union, 2003). On average, the number of Kyoto offsets that firms in the EU ETS were allowed to use was $13.5 \%$ of their free allocation, which amounted to around of 1.4 billion during Phase II. However, the exact number of offsets that could be used by firms varied by country, and sometimes even by industry. There were also differing rules regarding the use of the import quotas: Whereas some countries allowed their firms to use their quota at any time during Phase II of the EU ETS, which coincided with the period of the Kyoto Protocol, others stipulated that unused limits in one year could not be transferred to another year.

Because of the time delays discussed above, few offsets were available in the beginning of the 
phase, and it was not clear how many offsets would be available by the end of 2012 . To accommodate these issues, the European Commission decided in April, 2009, that firms could transfer any unused import limits to Phase III of the market (European Union, 2009). In addition, installations that for some reason were not given an import limit of $13.5 \%$ of free allocation in Phase II, or that entered the market only in Phase III, were given an additional import allowance for Phase III, which roughly amounted to another 300 million offsets. The total number of offsets that EU ETS firms are allowed to use in Phases II and III (i.e., between 2008 and 2020) is therefore around 1.7 billion.

While offsets generated during the Kyoto period can be banked for use after 2012, the reverse is not true: Offsets generated after 2012 could not be used for compliance in Phase II. ${ }^{8}$ However, because of the large amount of banked EUAs and the right to use up import limits through the end of Phase III, this no-borrowing constraint was not binding. Offsets generated after 2013 could thus be used by EU ETS firms during Phase III, but with some restrictions regarding the activities and locations of projects. Specifically, activities involving fluoroform (HFC-23) and nitric acid were excluded, and projects had to be located in a "least developed" country.

\subsection{Related literature}

Hieronymi and Schüller (2015) investigate how the existence of different emission permit classes affects firms' investment decisions between fossil and renewable sources of energy production. The authors apply a real options approach and find that having the option to use offsets increases the likelihood that a firm invest into a natural gas plant as opposed to wind energy, due to the lower compliance costs, and this effect increases with the import limit for offsets. Effectively, the provision to allow EU ETS firms to cover a part of their emission using Kyoto offsets amounts to a softening of the EU's climate policy. Vasa (2012) discusses policy changes that would lead to a different allocation of the rents from the EUA-CER spread, such as auctioning of the rights to use offsets.

Rahman and Kirkman (2015) focus on the CDM as such and find that the costs associated with generating CERs decrease with the scale of a project and its duration, vary across project types, and increase over time. Trotignon (2012) provides an overview of the regulatory conditions and analyses the use of offsets in the EU ETS in 2008 and 2009. He finds that some ETS firms used offsets during the first two years of Phase II, but that many firms did not, despite the price difference. Among

\footnotetext{
${ }^{8}$ This could theoretically have been the case for offsets generated between January and April of 2013, as this is the time when firms had to surrender allowances to cover their emissions for the year 2012.
} 
the offset importers, few exhausted their import limits. One possible explanation is the presence of transaction costs. Similarly, Braun et al. (2015) propose a model where multiple compliance targets co-exist, and show how differential transactions costs lead to a price spread between otherwise identical emission allowances.

A number of papers have looked at the EUA-CER spread from a technical perspective. For example, Nazifi (2013) employs a time-varying parameter model to relax the assumption of a fixed structural relationship between fundamentals and carbon assets. Among the main findings of that paper is that EUA price drivers affect CER prices in a different way and, as a result, a price spread emerges. Noteworthy is that this empirical analysis shows that institutional news and regulatory changes regarding the usability of CERs significantly affects the CER market; however the empirical model is ad-hoc and not structural. Koop and Tole (2013) employ flexible multivariate time series models to allow for time-varying parameters to study jointly model EUA and CER prices. They find evidence for contemporaneous causality with a dominant role of EUA futures, and that the relationship between the two types of carbon prices is changing over time due to the influence of macroeconomic factors such as the financial crisis. Qualitatively similar findings are obtained by Chevallier (2012), who uses a regime-switching model to show that business cycles are an important driver of the dynamics of the relationship. Kanamura (2016) studies the influence of carbon swap trading and energy prices on the relationship between EUA and CER prices. He shows that the correlation between EUA and CER prices has different drivers in different periods: while EUA-CER swap transactions explain a high correlation during periods with high EUA prices, falling energy prices explain the correlation between the two price series in the period of the financial crisis.

Mansanet-Bataller et al. (2011) identify a cointegration relationship between EUA and CER prices. Using a variance decomposition analysis, they report that a significant share of the variation of CER prices is explained by EUA price variations (but not vice versa), which is consistent with the assumptions that underlie our own model. 9 Similar to Nazifi (2013), information from the CDM pipeline is used in order to explain a share of the variation of the price spread, but without a structural derivation. To summarize, the papers discussed above capture the CER price process in a technical way, using different data and econometric models. Our paper builds on this literature in the sense that we recognize the presence of a systematic dynamic relationship between the EUA and CER prices, in which the former takes a leading role.

\footnotetext{
${ }^{9}$ In contrast, Mizrach (2012) and $\overline{\text { Nazifi }(2013)}$ find no cointegration relationship between EUA and CER prices.
} 


\section{Model}

In the following, we present the models we use in this paper: first, the structural CER price model and, second, the supporting cointegration and error correction analysis.

\subsection{CER price model}

We denote EUA prices by $P_{t}$ and prices for offsets from the Kyoto flexible mechanisms (either CERs or ERUs) by $C_{t}$. Global demand and supply of offsets at time $t$ are given by $d_{t}$ and $s_{t}$, respectively. We assume that the probability of noncompliance (i.e., that total emissions during Phase II exceed the total cap plus the import limit) is negligible, which was arguably the case after the decrease in business-as-usual emissions in the wake of the economic crisis of 2009. This means that a positive amount of allowances is transferred from Phase II to Phase III in expectation, which in turn implies that the allowance price in these two phases is continuous. This assumption is consistent with the empirical price data shown in Figure 1

We further define $S_{0}^{t} \equiv \sum_{k=0}^{t} s_{k}$ to be the cumulative offset supply by time $t$, which is observable, and $S_{t}^{T} \equiv \sum_{k=t+1}^{T} s_{k}$ to be the cumulative future offset supply until the terminal period for offset use, $T$. Due to the stochasticity of offset supply, $S_{t}^{T}$ is uncertain at time $t$. Likewise, $D_{0}^{t} \equiv \sum_{k=0}^{t} d_{k}$ refers to cumulative offset demand observed to date, and $D_{t}^{T} \equiv \sum_{k=0}^{t} d_{k}$ to uncertain future demand.

An important assumption in our model is that the time delay between an initial project proposal and the eventual delivery of certified offsets breaks the short-term link between the price and the expected supply of offsets. For example, an increase in the offset price in 2010 may lead to more projects being initiated, but we assume that this has no effect on the number of offsets that become available by the end of 2012. Conversely, projects that have incurred most of the associated fixed costs will continue to deliver offsets even if the offset price decreases, provided that the marginal costs of offset production are sufficiently low ${ }^{10}$ Because the UN pipeline data does not identify projects that are placed on hold and thus keeps them as active projects, our measure of expected supply does not incorporate price-induced reductions of the CER supply. This renders the expected excess offset supply published by the UN exogenous, rather than jointly determined with the offset

\footnotetext{
${ }^{10}$ Many offset projects consist in installing new production technology, which implies a combination of high fixed costs and low (or even negative) marginal abatement costs, compared to the situation without investment. In other words, once a more efficient production technology has been installed, it will be used independently of the CER price. Naturally, this assumption does not apply to CERs that are produced by means of fuel switching.
} 
price, such that it can be used as an explanatory variable. On the demand side, Annex B countries typically make their purchases depending on the success of their domestic abatement efforts, which we assume to be independent of the price of offsets. 11

As long as offsets can be used in the EU ETS, the relevant opportunity cost is the price of an EUA: Buying one offset allows firms to save one EUA to cover their emissions, which they can either sell on the market or bank into future periods $t>T$. If the EU ETS import limit has been reached, the opportunity cost for an offset depends on the willingness to pay by Annex B countries to reduce their Kyoto compliance gap by one unit, which could in theory be different to the price for EUAs. However, for lack of a different global reference price for $\mathrm{CO}_{2}$ emissions, and because countries could also use EUAs in lieu of offsets to comply with their Kyoto obligations, we assume that the willingness to pay for offsets both within and outside the EU ETS is given by the price for an EUA as long as the total number of supplied offsets does not exceed global demand related to the Kyoto process. If supply exceeds global demand (i.e., demand from the EU ETS plus Annex B countries), the willingness to pay for offsets will be related to their use in the context of the Paris Agreement, and possibly to private demand unrelated to any climate treaty.

Denoting the value for this "residual" use assigned to offsets at time $t$ as $V_{t}$, we obtain the following relationship between offsets and EUA prices in some terminal period T:

$$
\begin{aligned}
& C_{T}=P_{T} \quad \text { if } \quad S_{0}^{T} \leq D_{0}^{T} \\
& C_{T}=V_{T} \quad \text { if } \quad S_{0}^{T}>D_{0}^{T}
\end{aligned}
$$

At time $t<T$, firms are not sure whether offset supply will exceed global demand. The expected payoff from holding an offset at time $t$, subject to the available information at this time, is

$$
E_{t}\left[C_{T}\right]=E_{t}\left[P_{T}\right] \cdot \operatorname{Pr}\left(S_{0}^{t}+S_{t}^{T} \leq D_{0}^{t}+D_{t}^{T}\right)+E_{t}\left[V_{T}\right] \cdot \operatorname{Pr}\left(S_{0}^{t}+S_{t}^{T}>D_{0}^{t}+D_{t}^{T}\right)
$$

Let $x_{t} \equiv S_{t}^{T}-D_{t}^{T}$ refer to the future cumulative excess supply of offsets between $t$ and $T$, which is a stochastic variable distributed according to the probability density function $f\left(x_{t}\right)$. This allows us

\footnotetext{
${ }^{11}$ At very high offset prices, countries might prefer to institute new climate policies. However, the time lag between the proposition of new policy and results in terms of abatement may take years as well. In any case, the prices of offsets were below expectations throughout the Kyoto Phase, and certainly well below abatement costs e.g. by fuel switching.
} 
to express (3) as

$$
E_{t}\left[C_{T}\right]=E_{t}\left[P_{T}\right] \cdot \int_{-\infty}^{D_{0}^{t}-S_{0}^{t}} f\left(x_{t}\right) d x_{t}+E_{t}\left[V_{T}\right] \cdot \int_{D_{0}^{t}-S_{0}^{t}}^{\infty} f\left(x_{t}\right) d x_{t}
$$

Using the central limit theorem and defining the expectation and standard deviation of $x_{t}$ as $\mu_{t}^{x}$ and $\sigma_{t}^{x}$, respectively, the variable $Q_{t} \equiv\left(x_{t}-\mu_{t}^{x}\right) / \sigma_{t}^{x}$ has a standard normal distribution such that we can express (4) as

$$
E_{t}\left[C_{T}\right]=E_{t}\left[P_{T}\right] \cdot \int_{-\infty}^{\left(D_{0}^{t}-S_{0}^{t}-\mu_{t}^{x}\right) / \sigma_{t}^{x}} \phi\left(Q_{t}\right) d Q_{t}+E_{t}\left[V_{T}\right] \cdot \int_{\left(D_{0}^{t}-S_{0}^{t}-\mu_{t}^{x}\right) / \sigma_{t}^{x}}^{\infty} \phi\left(Q_{t}\right) d Q_{t}
$$

or, equivalently, as

$$
E_{t}\left[C_{T}\right]=E_{t}\left[P_{T}\right] \cdot \Phi\left(\frac{D_{0}^{t}-S_{0}^{t}-\mu_{t}^{x}}{\sigma_{t}^{x}}\right)+E_{t}\left[V_{T}\right](1-\Phi(\cdot))
$$

where $\phi(\cdot)$ and $\Phi(\cdot)$ refer to the p.d.f and c.d.f. of the standard normal distribution, respectively, and their argument is the standardized expected excess demand until period $T$.

Arbitrage implies that the prices of offsets and EUAs have to be equal to their discounted expected prices in period $T$, where $r$ is the risk-free rate of discount: 12

$$
C_{t}=P_{t} \cdot \Phi\left(\frac{D_{0}^{t}-S_{0}^{t}-\mu_{t}^{x}}{\sigma_{t}^{x}}\right)+e^{-r(T-t)} E_{t}\left[V_{T}\right] \cdot(1-\Phi(\cdot))
$$

Eq. (6) is our offset pricing equation and states that the spot price of an offset is equal to the spot price of an EUA ${ }^{13}$ times the probability that the total supply of offsets is insufficient to cover the global demand (the sum of EU ETS firms and Annex B countries). In that case, offsets and EUAs are fungible assets and their prices converge. If, on the other hand, the market expects an oversupply of Kyoto offsets, then offsets should trade at a significant discount relative to EUAs, assuming that

\footnotetext{
${ }^{12}$ Our focus is on pricing CERs based on their opportunity costs, and we abstract from the risk premia of EUAs and CERs by assuming that investors are risk-neutral. Under risk neutrality, the stochastic discount factor, which is the basis of pricing assets under risk, reduces to the rate of time preference. Using notation from Cochrane (2009), the price of an asset is given by $p=E[m x]$, where $m$ is the stochastic discount factor and $x$ the payoff. Under risk neutrality, the marginal utility of income is the same across all states of the world, such that the pricing equation reduces to $p=m \cdot E[x]$. In our context, the discount factor becomes $m=e^{-r(T-t)}$, which results in eq. (6).

${ }^{13}$ Note that the pricing equation holds for future prices as well, provided that the delivery period is no later than $T$. Due to the import rules, CER futures with delivery beyond $T$ would be priced according to only the second half of the price equation, since use in the EU ETS or Kyoto is not an option.
} 
$E_{t}\left[V_{T}\right]<P_{t}$. If there is no use for Kyoto offsets outside Annex B countries, then $V_{T}=0$.

Our pricing equation (6) is qualitatively similar to pricing equations derived for EUAs during the first phase of the EU ETS (Carmona et al., 2009; Chesney and Taschini, 2012; Hintermann, 2012). These equations express the price for an EUA as a function of the penalty for noncompliance and the probability that the first-phase cap turned out to be binding. A common feature of these price equations is that they are based on models of discontinuous markets. In the first phase of the EU ETS, the discontinuity was due to the no-banking provision, which made it impossible to bank unused allowances into the second market phase. At the end of the first phase, allowances were therefore either worth nothing or the penalty for noncompliance. In the present context, the discontinuity stems from the fact that offsets cannot be used in the EU ETS beyond 2020. Any unused offsets are then sold at the price of the outside option $V_{T}$ (which could be zero).

In our data, we do not observe $D_{0}^{t}$ and $D_{t}^{T}$ separately and thus cannot compute $\mu_{t}^{x}$ directly. However, the numerator in (6) is the total expected excess demand, which we can compute based on our data as

$$
D_{0}^{t}-S_{0}^{t}-\mu_{t}^{x}=E_{t}\left[D_{0}^{T}-S_{0}^{T}\right]
$$

There is no empirical information about what $\sigma_{t}^{x}$ should be. However, if only few offsets have been issued, the uncertainty associated with delays and attrition is arguably greater than if a significant share of the announced offsets already exists. As $t \rightarrow T$, the uncertainty vanishes, at least in theory ${ }^{14}$ To account for this, we specify the uncertainty about future excess supply as a decreasing function of the share of the total expected offsets that have actually been issued by time $t$, and include $\sigma$ as a free parameter in the model:

$$
\sigma_{t}^{x}=\sigma \cdot \frac{S_{0}^{t}+E\left[S_{t}^{T}\right]}{S_{0}^{t}} \text { for } \quad S_{0}^{t}>0
$$

The parameter $\sigma$ represents the standard deviation of the expected excess supply if all announced offsets have been issued; the remaining uncertainty is therefore entirely due to the demand side.

Last, (6) depends on market participants' expectation of the outside value of offsets, $V_{T}$. We

\footnotetext{
${ }^{14}$ Note that this is true only if information about offset supply is instantaneously available. In reality and as discussed above, monitoring takes place irregularly and with a delay, such that eve at $t=T$, the exact number of offsets available is not known.
} 
leave this as a free parameter, but allow it to be updated after the Copenhagen negotiations about a post-Kyoto agreement failed in December 2009.15 We thus include a dummy, $D_{t}^{c o p}$, that is equal to zero before December 2009, and one thereafter. This leads us to the following specification:

$$
C_{t}=P_{t} \cdot \Phi\left(\frac{E_{t}\left[D_{0}^{T}-S_{0}^{T}\right]}{\sigma \cdot E\left[S_{0}^{T}\right] / S_{0}^{t}}\right)+e^{-r(T-t)}\left[V_{0}+V_{c o p} \cdot D_{t}^{c o p}\right] \cdot(1-\Phi(\cdot))
$$

In our empirical section, we calibrate the free parameters $\sigma, V_{0}$ and $V_{c o p}$ by estimating (9) by nonlinear least squares.

\subsection{Cointegration and error correction}

To obtain a quasi-external validation of our pricing model, we employ a cointegration and error correction analysis. This analysis does not rely on the two main assumptions made in the development of our pricing equation: The expected supply of offsets does not respond to the current price for offsets, and the EUA price drives the CER price but not vice versa. The idea of the theoretical model we put forward is captured here in a different manner. If the probability that a CER can be substituted for an EUA at the end of the relevant time period is high, the two price series would be closely related and, thus, possibly cointegrated. In contrast, the smaller this probability is, the less related the prices will be, which should result in a lack of cointegration. In case a cointegration relationship exists, the estimation of an error correction model (ECM) is useful.

Rather than conducting this analysis using the entire sample, we investigate how this relationship changes over time. To do this, we start with an initial subsample and subsequently add observations, while holding the starting point of the sample fixed. ${ }^{16}$ For each subsample, we perform the standard cointegration and error correction procedure described by Engle and Granger (1987). For this, we regress the EUA price on the CER price and compute the residuals. This is commonly referred to as estimating the long-run relationship; thus, the residual series measures the distance or the equilibrium error between the two variables under consideration. If a cointegration relationship exists - or in other words, an equilibrium relationship - the residual series will be stationary.

\footnotetext{
${ }^{15}$ During the Conference of Parties (COP) meeting in Copenhagen, it became clear that there would be no continuation of the Kyoto Protocol in the sense that there was no binding multinational treaty that specified mandatory emissions reductions. However, some countries (including all members of the EU) agreed to voluntary emissions reductions.

${ }^{16}$ This procedure is referred to as "forward recursive" and is very common in the applied time series literature. Most recently, Phillips and Yu (2011) employ this procedure in order to identify origin and collapse date of stock market bubbles. This further development of so-called cointegration based tests for speculative bubbles also involves applications of unit root tests.
} 
We then conduct a two-part analysis. First, we apply a Phillips-Perron unit root test of no cointegration, against a null hypothesis of a stationary residuals (which implies the presence of cointegration). The forward-recursive application of this procedure yields a sequence of p-values, which can then be used to illustrate a potential change in the cointegration relationship over time. Second, we estimate an error correction model, which captures how the CER price responds to the equilibrium error. If an equilibrium relationship exists between CER and EUA price, the coefficient of the equilibrium error (which is also called the adjustment parameter) enters the error correction model in a statistically significant manner. This procedure is applied forward recursively and allows us to track the development of both the adjustment speed and the associated p-value over time. More technical details about the cointegration and error correction analysis can be found in the appendix.

\section{Data}

We obtained a monthly series of the UN's "CDM and JI pipeline" ${ }^{17}$ The data contains information about all projects that have reached at least the validation stage. For each project, the expected number of offsets is computed by the end of 2012 and by the end of 2020 . The data also contains information about actual offset issuance, project type, location etc.

The expected number of offsets is based on the information contained in the project design document (PDD). To correct for delays and to incorporate new information about the issuance success (i.e., the productivity) of a project, we make the following corrections:

\section{Credit start of projects that have not yet been registered}

The PDD of each project contains an expected credit start, which is the expected time when a project starts to actually reduce emissions and thus generates emission offsets. This credit date is only adjusted if a revised PDD is submitted, or if the project is registered. Due to delays in the CDM or JI process (see above), the projected credit start is quite often before the current month of observation, even though the project has not yet been registered (and thus the credit start cannot have happened). Whenever this is the case, we replace the expected project date with the current date. For example, suppose that the CDM pipeline of July 2011 lists an unregistered project with a projected credit start

\footnotetext{
${ }^{17}$ Available at www.cdmpipeline.org, last accessed in January 2016. The website only contains the current pipelines. We thank the UN's Jorgen Fenhann for providing us with the historic pipelines.
} 
in 2010. In this case, the expected project start is moved forward to July 2011.

\section{Issuance success of registered projects}

Once a project is registered, it begins to produce offsets. After each monitoring period, the number of generated offsets during this period is listed in the (verified) monitoring report. This number may be greater or smaller than the number expected based on the PDD due to unforeseen shocks or events; however, the "expected offsets by 2012/2020" series in the CDM and JI pipelines do not account for this new information, but continue to list the expected offsets based on the PDD. To correct for the heterogeneity in issue success, we adjust the number of expected offsets using the information from the monitoring report at time $\bar{t}$ in the following way:

Corrected expected (exp.) issuance (iss.) by $T=$

(Exp. iss. by $T-$ Exp. iss. by $\bar{t}) \cdot\left(\frac{\text { Observed iss. by } \bar{t}}{\text { Exp. iss. by } \bar{t}}\right)+$ iss. by $\bar{t}$

For example, suppose that a project started in 2009, and based on its PDD it is expected to deliver 250,000 offsets per year, or 1 million offsets by the end of 2012. However, the monitoring report for the first year $(\bar{t}=$ December 31,2009$)$ shows that instead of the projected 250,000, only 200,000 offsets were produced. The formula above then computes the corrected expected issuance using this issuance success of $80 \%$, which results in a corrected expected issuance of $(750 \mathrm{kt} \cdot 0.8+200 \mathrm{kt}=)$ $800 \mathrm{kt}$ by 2012. An equivalent correction applies to the number of expected offsets by 2020 .

The original data in the CDM and JI pipelines refer to so-called "primary" offsets, which are subject to the full delivery risk. Because the adjustment carried out in (10) removes an important part of the delivery risk, the resulting data more closely describes actually expected offsets. This makes it consistent with the empirical analysis, which is based on secondary CER prices, i.e, prices for CERs that have already been issued and therefore contain no delivery risk.

\section{Restrictions for Phase III}

After the end of Phase II, offsets from projects involving the reduction of HFC-23 or nitric acid were excluded for use in the EU ETS or the Kyoto market. This excluded a significant share of 
the expected offsets by 2020, as shown in Figure A5 in the appendix. Furthermore, only projects in "least developed countries" were allowed for continued use (European Union, 2009), which excluded offsets from projects e.g. in China. Issuance of CERs or ERUs from projects that did not meet these criteria was still possible, but only for the emissions reductions that took place before 2013 . We corrected the "expected by 2020" series for the Phase III-restrictions by excluding offsets that did not meet the inclusion criteria.

We obtained estimates for offset demand from Bloomberg, which cites the World Bank as one of the sources. Demand estimates are split up between demand from EU ETS firms, based on the offset import rules and Annex B countries. The data furthermore differentiate between demand by 2012, and demand by 2020. However, expectations for the latter were not updated every month, but only when new information became available.

Figure 3: Supply of offsets

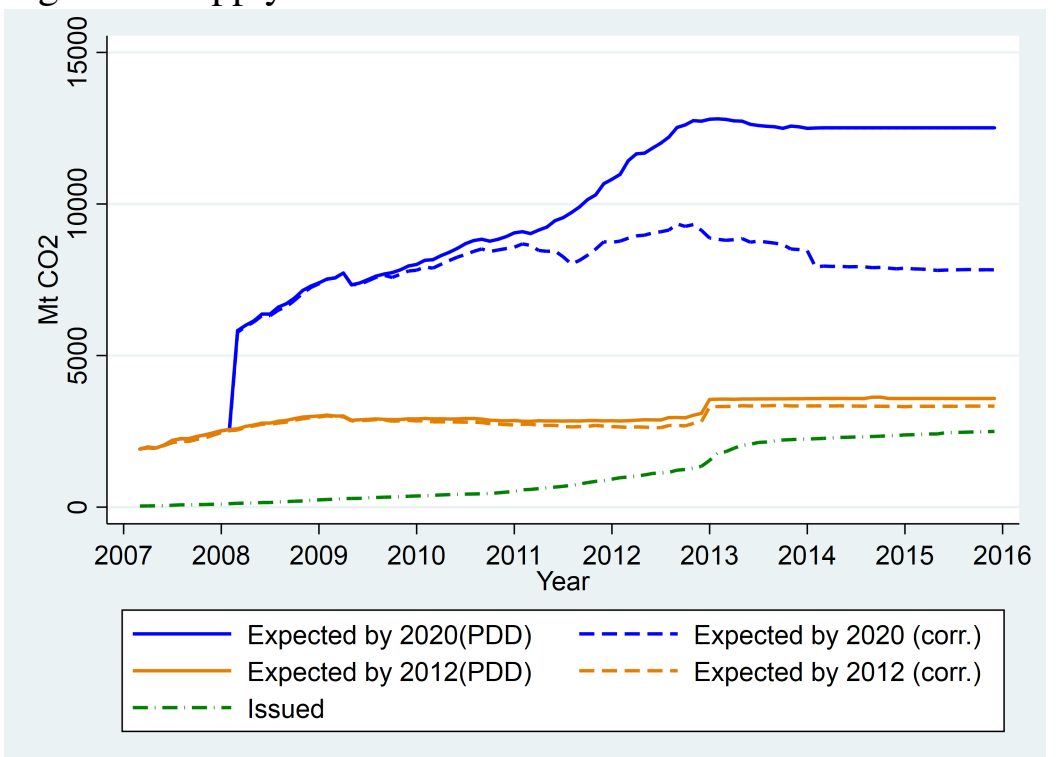

Source: Own illustration based on data from UN CDM/JI pipelines (see footnote 17).

Figure 3 presents the the original and the corrected estimates for offset supply (sum of CERs and ERUs) by 2012 and by 2020 over time, along with the actual issuance. The drop in the supply estimates by 2020 is predominantly due to the restrictions imposed for Phase III. Note that although the difference between projected and actual offset supply decreases over time, the two lines do not actually converge. This suggests that once the CER price dropped to very low levels, some projects either halted operation or stopped engaging in (costly) monitoring reports, but without notifying the CDM board that the project had been abandoned 18

\footnotetext{
${ }^{18}$ Although this means that the UN data overestimates the true expected offset supply, from an empirical perspective
} 
Figure 4 shows the expected demand for offsets. Whereas demand and supply were of similar magnitude if computed by 2012, the surge in supply by 2020 (accompanied by a much smaller increase in demand) resulted in a significant expected excess supply.

Figure 4: Expected excess demand for offsets (demand minus supply)

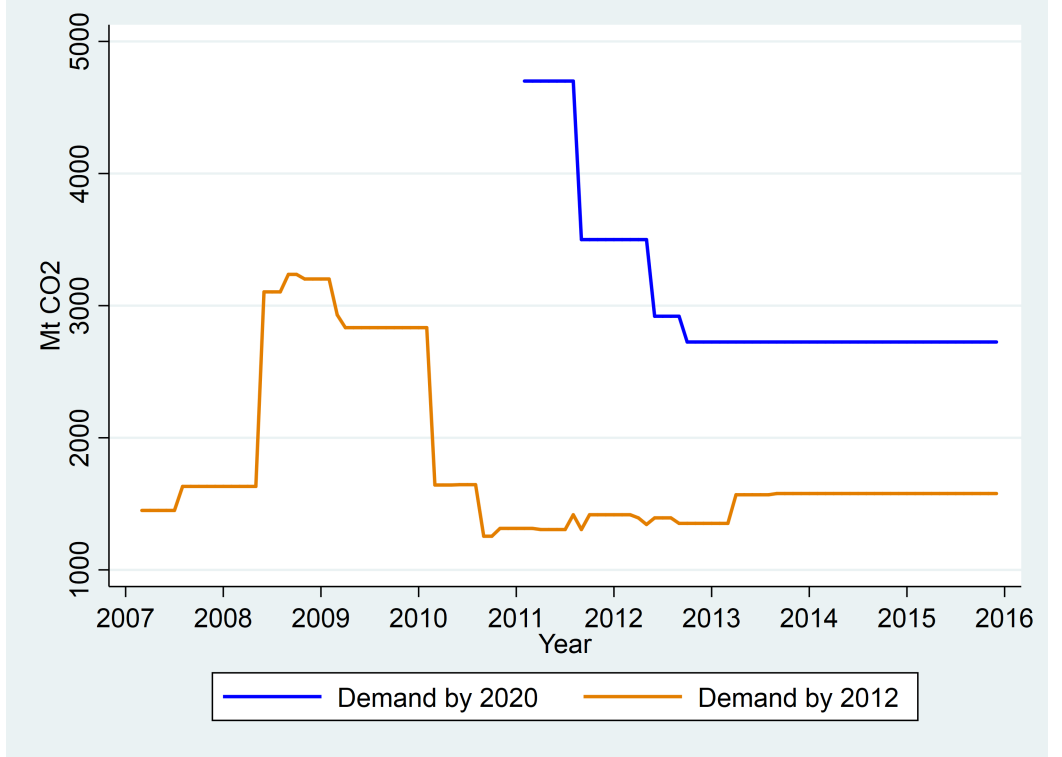

Source: Own illustration based on World Bank data as reported by Bloomberg.

We use next-December futures for EUAs from the European Energy Exchange (EEX). For the CER price, we use the one-year future from Nordpool until February 2008, and a broker price from Reuters thereafter (the Nordpool price series ends at some point; at the switch, the two prices are identical). We accessed these prices via Thomson Reuters Datastream.

Summary statistics of all variables are presented in Table 1 . Because the offset supply data follows a monthly frequency, we use monthly values for our analysis. The trading volumes (aggregated to the month) imply that both assets were traded at a sufficiently high frequency to justify the international arbitrage underlying eq. (6). 19

it is preferable to not include a price-induced response in offset supply, as we assume that the supply of offsets drives the price, but not vice versa. In this sense, the UN supply estimates can be viewed as a quasi-exogenous (i.e., priceinsensitive) instrument for true CER supply.

${ }^{19}$ The longest price series for CERs is supplied by Thomson Reuters, which includes OCT transactions. However, this price series does not include trading volumes. To get information about the volume of trades, we use data from EEX and Bluenext, which covers a shorter time period. 
Table 1: Summary statistics

\begin{tabular}{lcccccc}
\hline Variable & Obs & Unit & Mean & Std. Dev. & Min & Max \\
\hline Exp. offset supply by 2012 & 103 & $\mathrm{Mt} \mathrm{CO}_{2}$ & $2^{\prime} 920$ & 346 & $2^{\prime} 037$ & $3^{\prime} 351$ \\
Exp. offset supply by 2020 & 103 & $\mathrm{Mt} \mathrm{CO}_{2}$ & $7^{\prime} 561$ & $1^{\prime} 797$ & $2^{\prime} 037$ & $9^{\prime} 342$ \\
Verified offsets & 103 & $\mathrm{Mt} \mathrm{CO}_{2}$ & $1^{\prime} 109$ & 906 & 51 & $2^{\prime} 498$ \\
Exp. offset demand by 2012 & 103 & $\mathrm{Mt} \mathrm{CO}_{2}$ & $1^{\prime} 803$ & 616 & $1^{\prime} 255$ & $3^{\prime} 237$ \\
Exp. offset demand by 2020 & 59 & $\mathrm{Mt} \mathrm{CO}_{2}$ & $3^{\prime} 091$ & 656 & $2 ' 725$ & $4^{\prime} 700$ \\
CER price & 103 & Euro/tCO & 7.57 & 6.70 & 0.14 & 21.05 \\
CER volume & 78 & $\mathrm{kt} \mathrm{CO}$ & $1^{\prime} 703$ & $1^{\prime} 679$ & 2 & $66^{\prime} 929$ \\
EUA price & 103 & Euro/tCO $_{2}$ & 11.86 & 6.18 & 3.55 & 27.38 \\
EUA volume & 91 & $\mathrm{kt} \mathrm{CO}$ & $19^{\prime} 932$ & $399^{\prime} 095$ & 142 & $2266^{\prime} 732$ \\
\hline
\end{tabular}

Sample period: June 2007 until December 2015. Sources: Offset supply from the UN's JI and CDM pipelines; offset demand from the Bloomberg; CER and EUA prices and volumes from Thomson Reuters Datastream; volumes are sum of transactions at EEX and Bluenext.

\section{Results}

We start by presenting the calibration results and then engage in the computation of counterfactual CER prices based on different assumptions about the distribution of demand and supply for offsets. Finally, we compare our results with those of a cointegration analysis to provide some external support of our theory.

\subsection{Calibration}

The time period $T$ marks the relevant time horizon for the demand and supply of offsets. As discussed in section 2, the relevant time horizon is December 2012 in the beginning, but switches to December 2020 when the EU decided to allow for the transfer of any unused import limits to Phase III. Rather than just using April 2009 as switching date, we "let the data speak" in order to learn about how information is processed in this market. We thus estimate (9) for all switches in the relevant time horizon' between January 2008 and December 2012. The model fit as measured by the Bayesian Information Criterion is highest if the relevant time horizon switched to 2020 horizon in December of 2008, which is five months prior to the issuance of the Amended Linking Directive ${ }^{20}$ The fact that the revealed switch occurs before the publication of the Directive could be explained by the content of the directive being discussed several months before it was finalized. In addition, there was a public

\footnotetext{
${ }^{20}$ Using Akaike's Information Criterion and the average absolute error leads to the same switching month.
} 
controversy about the additionality regarding offsets from HFC-23 projects, which were banned by the directive, and which likely increased its salience.

The first column in Table 2 shows the calibrated values based on switching the series in December of 2008. The second column displays the results if the switching date is set for April 2009, the publication date of the Amended Linking Directive. The results are qualitatively similar, indicating that the are not overly sensitive to the exact switching month.

Table 2: Calibration results

\begin{tabular}{ccc}
\hline & Switch in Dec. 2008 & Switch in Apr. 2009 \\
\hline$V_{0}$ & 14.89 & 14.32 \\
& $(1.30)$ & $(1.27)$ \\
$V_{\text {cop }}$ & -14.11 & -13.55 \\
& $(2.68)$ & $(2.70)$ \\
$\sigma$ & 2,616 & 2,629 \\
& $(4,122)$ & $(4,168)$ \\
\hline
\end{tabular}

Note: Coefficient estimates based on nonlinear regression of specification (9) using Stata Version 15. Standard errors given in parenthesis.

The fact that the value of the outside option decreases from around 14 Euros to a number that is statistically not different from zero (i.e., the sum of the coefficietns on $V_{0}$ and $V_{\text {cop }}$ ) suggests that the failure of an agreement for a post-Kyoto treatment lead to a downward adjustment of the outside value of offsets to zero. In the absence of a formalized mechanism that allows countries or firms to engage in emissions reduction efforts abroad, offsets generated via the CDM and JI mechanisms can only be used for compliance within the EU ETS or Annex B parties, and are worthless otherwise.

Figure 5 shows the predicted CER price, along with the EUA price, based on the calibrated parameter values. The base model (9) captures the main price movements. Allowing the outside value of offsets to be updated annually by including yearly dummies in the term in brackets, rather than only after the COP meeting in Copenhagen in December 2009, leads to a much better model fit, suggesting that the pricing equation (9) does not capture the full price process. However, because we are mainly interested in proposing a mechanism that underlies the CER price rather than producing a price prediction per se (which could be accomplished by including he lagged CER price as an explanatory variable for the current CER price, but at the cost of foregoing any attempt for an economic explanation), we proceed the analysis with the predictions of the parsimonious base model. 
Figure 5: Prices and predictions

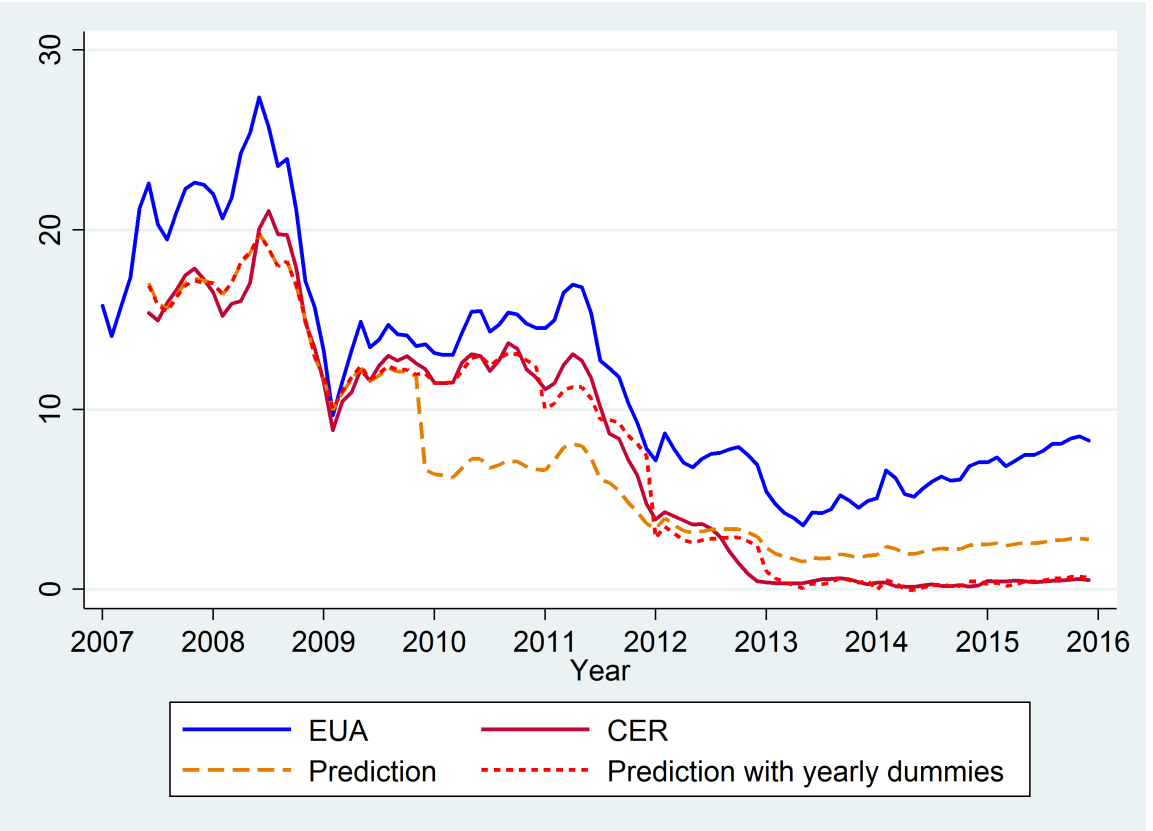

Source: EUA and CER prices from Thomson Reuters Datastream; predictions based on own calculations.

\subsection{Counterfactual CER prices}

Using our calibrated values, we can compute CER prices under counterfactual assumptions about offset demand and supply. First, we examine the sensitivity of the resulting CER price with respect to a change in the expected excess demand. For example, the EU could have chosen a different import limit, or Annex B countries could have achieved different abatement amounts at home (which would have directly affected their expected demand for offsets). For this "what if"-exercise, we hold the EUA price constant. The left panel in Figure 6 shows the CER price prediction for counterfactual scenarios where excess demand is larger or smaller by 4 Gt. The effect of this sizable change in excess demand (recall that the actual import limit to the EU ETS is $1.7 \mathrm{Gt}$ ) on the CER price is rather small. The reason is that in the beginning of Phase II, the most important determinant in the CER pricing equation is the large uncertainty about future supply and demand of offsets, which is in the denominator of $\Phi(\cdot)$ in (9), and which dampens the effect of even substantial changes in expected excess demand ${ }^{21}$ However, the more information that is revealed, and as a consequence, the smaller the uncertainty about future excess demand, the larger is the effect of a change in excess demand, as can be seen in the figure.

The right panel in Figure 6 shows the sensitivity with respect to the standard deviation of excess

\footnotetext{
${ }^{21}$ Given the large standard deviation $\sigma_{t}, \Phi(\cdot) \approx 0.5$ unless the shift in the expected excess demand becomes very large.
} 
Figure 6: Counterfactual predictions for different expected excess demand
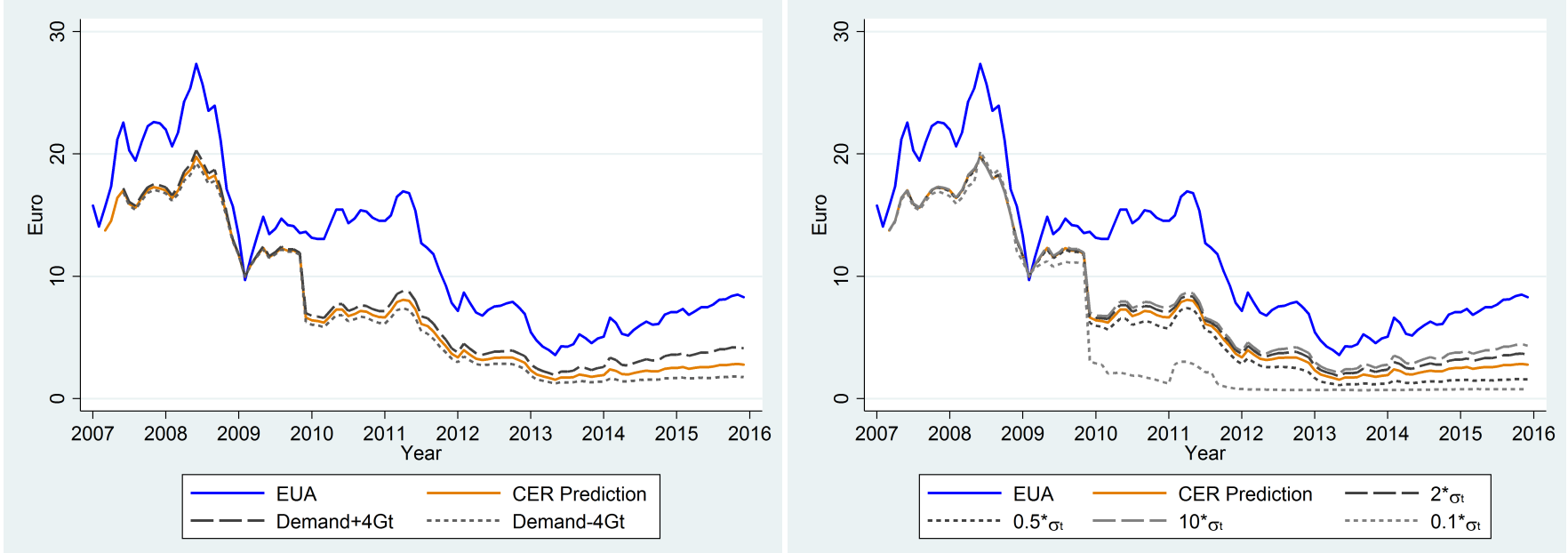

Source: EUA price from TR Datastream; demand data from Bloomberg; predictions based on own calculations.

offset demand. The effect of doubling or halving $\sigma_{t}$ is relatively small, and even multiplying $\sigma_{t}$ by a factor of 10 does not significantly affect the CER price. However, if $\sigma_{t}$ were smaller by a factor of 10, CER price would have approached zero much sooner, namely after the COP meeting at the end of 2009. This is the moment when it became clear that there would be no binding international agreement after the Kyoto period, thus basically eliminating the value of offsets if they cannot be used within the Kyoto framework (including the EU ETS). Our results imply that the CER price did not immediately respond to this change in the future institutional background due to the large uncertainty surrounding the demand and supply of offsets. This suggests a role for institutions that increase the transparency on both the demand and the supply side for future offset programs or when linking domestic cap-and-trade markets, e.g., in the context of the Paris agreement.

\subsection{Cointegration and error correction results}

Having presented the results of our theoretical model, we now turn to the results of the cointegration and error correction analysis. In the context of model (6), a break in the cointegration relationship between the two prices can be interpreted in the sense that the import limit is binding, and thus that the probability of CERs and EUAs being fungible assets becomes small. This would imply that an equilibrium relationship no longer exists, which would be accompanied by both a decrease in the magnitude and the loss of significance of the adjustment speed coefficient. The left panel in Figure 7 shows this probability, $\Phi(\cdot)$, along with the adjustment speed parameter. The probability $\Phi(\cdot)$ drops sharply towards the end 2012, which coincides with a similarly decline in the (absolute) value of the 
adjustment speed parameter, $\alpha$. The right panel shows that the decline in $\Phi(\cdot)$ also coincides with a loss of significance of the adjustment speed paramerer as well as a loss of cointegration. ${ }^{22}$ The fact that this cointegration and error correction analysis yields a qualitatively similar result in terms of when the two prices diverged lends additional support for our model.

\section{Conclusions}

In this paper, we develop a theory of CER price formation. We derive a pricing equation that specifies the CER price as a weighted average of the EUA price and the outside value of offsets, with the weight given by the probability that the limit for using offsets in the EU ETS turns out to be binding. We calibrate our model using monthly data about offset supply from the UN's CDM/JI pipelines, which is a rich data source that, to our knowledge, has not been used to investigate CER price determination to date. Our base model, which only contains three calibrated parameters, explains a significant share of the CER price variation. Our findings are further supported by a series of cointegration tests that indicate that the moment when the cointegrating relationship between EUAs and CERs breaks down coincides with a sharp increase in the probability that the offset import limit turns out to be binding. The existing literature on the price spread either applies a-theoretical time series approaches only or emphasises the role of transaction cost. Thus, the former does not provide a structural explanation for the observed spread while the latter argument is not able to explain the time-varying nature of the price spread.

Using our calibrated model, we engage in a "what if" exercise where we analyze the sensitivity of the offset price to changes in the level of expected excess demand, and in the uncertainty surrounding the supply and demand of offsets. For example, the EU could have chosen a different offset usage limit for the EU ETS, or Annex B countries could have been asked to publish their projected offset demand in the context of the Kyoto protocol more frequently. We find that even significant changes in the level of expected demand and/or supply lead to only minor changes in the resulting CER price. In contrast, (significantly) reducing the uncertainty surrounding demand and supply of offsets increases the dependency of the CER price to variations in demand and supply, as well as to

\footnotetext{
${ }^{22}$ Note that each element in the sequences of $p$-values and adjustment speed parameter estimates represents the value at the end of each subsample. The cointegration tests indicates that the cointegration collapses some time after the loss of significance of the adjustment speed parameter. This result reflects that the cointegration test requires a certain number of "non-cointegrated" observations before the null of no cointegration is no longer rejected.
} 
changes in international climate policy. In particular, if the uncertainty about excess supply had been significantly smaller, the CER price would have dropped to zero immediately after the negotiations for a post-Kyoto agreement collapsed in December of 2009.

Our results suggest that uncertainty plays an important role when linking two emission trading systems, in particular if institutional and regulatory barriers disconnect prices and quantities. In such a situation, market participants are unsure if the market will be long or short, unless there are specifically designed mechanisms that reveal this type of information. Such mechanisms were absent in the CER/ERU markets, and as a consequence, the price for offsets remained high even when (in hindsight) it was clear that aggregate supply far exceeded demand. Thus, important policy lessons emerge from this analysis.

Uncertainty about whether (and/or when) two cap-and-trade markets will be fully linked is a natural scenario in the future if political concerns exist about unlimited linking domestic markets in the context of the Paris Agreement. Under full linking, the more stringent market "inherits" the climate policy of the less stringent market and may furthermore import price volatility due to regulatory changes abroad (Green, 2017). At the same time, very limited linking may not be interesting from an economic perspective since the expected costs savings would be minor. As a consequence, an intermediate level of linking as analyzed in this paper may be a likely outcome, such that linking under uncertainty may become the rule rather than the exception in future climate policy.

Our model could be applied to different contexts where assets are fungible in principle, but subject to constraints which may or may not turn out to be binding. Examples include markets for electricity futures where spot prices converge if and only if connection constraints are nonbinding, or the convergence of prices for natural gas futures in North America and the rest of the world depending on the capacity of gas export terminals.

\section{References}

Braun, Nathan, Timothy Fitzgerald, and Jason Pearcy (2015) “Tradable Emissions Permits with Offsets," in Marc Gronwald and Beat Hintermann eds. Emissions Trading as a Policy Instrument: Evaluation and Prospects: MIT Press, pp. 239-266.

Carmona, René, Max Fehr, and Juri Hinz (2009) “Optimal stochastic control and carbon price for- 
mation," SIAM Journal on Control and Optimization, Vol. 48, No. 4, pp. 2168-2190.

Chesney, Marc and Luca Taschini (2012) “The endogenous price dynamics of emission allowances and an application to CO2 option pricing," Applied Mathematical Finance, Vol. 19, No. 5, pp. $447-475$.

Chevallier, Julien (2011) Price relationships in the EU emissions trading system, pp. 212-220: IGI Global.

(2012) "EUAs and CERs: Interactions in a Markov regime-switching environment," Economics Bulletin, Vol. 32, No. 1, pp. 86-101.

Cochrane, John H (2009) Asset pricing: Revised edition: Princeton university press.

Ellerman, A Denny, Claudio Marcantonini, and Aleksandar Zaklan (2016) "The European Union Emissions Trading System: Ten Years and Counting," Review of Environmental Economics and Policy, Vol. 10, No. 1, pp. 89-107.

Engle, Robert F. and Clive W.J. Granger (1987) "Co-Integration and Error Correction: Representation, Estimation, and Testing," Econometrica, Vol. 55, No. 2, pp. 251-276.

European Union, (2003) "Directive 2003/87/EC of the European Parliament and of the Council of 13 October 2003."

(2009) "Directive 2009/29/EC of the European Parliament and of the Council of 23 April 2009."

Green, Jessica F (2017) “Don’t link carbon markets.,” Nature, Vol. 543, No. 7646, pp. 484-486.

Grüll, Georg and Luca Taschini (2012) "Linking emission trading schemes: a short note," Economics of Energy \& Environmental Policy, Vol. 1, No. 3, pp. 31-38.

Hieronymi, Philipp and David Schüller (2015) “The Clean-Development Mechanism, stochastic permit prices and energy investments," Energy Economics, Vol. 47, pp. 25-36.

Hintermann, Beat (2012) "Pricing emission permits in the absence of abatement," Energy Economics, Vol. 34, No. 5, pp. 1329-1340. 
Hintermann, Beat and Marc Gronwald (2015) “The EU ETS," in Marc Gronwald and Beat Hintermann eds. Emissions trading as a policy instrument: MIT Press, pp. 15-23.

Hintermann, Beat, Sonja Peterson, and Wilfried Rickels (2016) "Price and Market Behavior in Phase II of the EU ETS: A Review of the Literature," Review of Environmental Economics and Policy, Vol. 10, No. 1, pp. 108-128.

Kanamura, Takashi (2016) "Role of carbon swap trading and energy prices in price correlations and volatilities between carbon markets," Energy Economics, Vol. 54, pp. 204-212.

Koop, Gary and Lise Tole (2013) "Modeling the relationship between European carbon permits and certified emission reductions," Journal of Empirical Finance, Vol. 24, pp. 166-181.

Mansanet-Bataller, Maria, Julien Chevallier, Morgan Hervé-Mignucci, and Emilie Alberola (2011) "EUA and sCER phase II price drivers: Unveiling the reasons for the existence of the EUA-sCER spread," Energy Policy, Vol. 39, No. 3, pp. 1056-1069.

Mizrach, Bruce (2012) "Integration of the global carbon markets," Energy Economics, Vol. 34, No. 1, pp. 335-349.

Nazifi, Fatemeh (2013) “Modelling the price spread between EUA and CER carbon prices," Energy Policy, Vol. 56, pp. 434-445.

Phillips, Yangru Wu, Peter C.B. and Jun Yu (2011) "Explosive Behavior in the 1990s NASDAQ: When did Exuberance escalate Asset Values?" International Economic Review, Vol. 52, No. 1, pp. 201-226.

Rahman, Shaikh M. and Grant A. Kirkman (2015) "Costs of certified emission reductions under the Clean Development Mechanism of the Kyoto Protocol," Energy Economics, Vol. 47, pp. 129-141.

Trotignon, Raphael (2012) "Combining cap-and-trade with offsets: lessons from the EU-ETS," Climate Policy, Vol. 12, No. 3, pp. 273-287.

Trotignon, Rafael and Benoit Leguet (2009) “How Many CERs by 2013?”. Mission Climat Working Paper Nr. 2009-5. 
UNFCCC, (2006) "Report of the Conference of the Parties serving as the meeting of the Parties to the Kyoto Protocol on its first session, held at Montreal from 28 November to 10 December 2005. Addendum, Part Two: Action taken by the Conference of the Parties serving as the meeting of the Parties to the Kyoto Protocol at its first session.” FCCC/KP/CMP/2005/8/Add.2.

(2013) “Afforestation and reforestation projects under the Clean Development Mechanism: A reference manual.” http://www.unfccc.int.

(2015a) “CDM project cycle procedure.” CDM-EB65-A32-PROC, Version 9.0.

(2015b) “CDM project standard.” CDM-EB65-A05-STAN, Version 9.0.

(2015c) “CDM validation and verification standard.” CDM-EB65-A04-STAN, Version 9.0.

Vasa, Alexander (2012) "Certified emissions reductions and CDM limits: revenue and distributional aspects," Climate policy, Vol. 12, No. 6, pp. 645-666. 


\section{A Additional tables and figures}

Table A1: List of acronyms

\begin{tabular}{ll}
\hline CDM & Clean Development Mechanism \\
CDM EB & Executive Board of the Clean Development Mechanism \\
CER & Certified emissions reduction \\
DOE & Designated operational entity \\
DNA & Designated national authorities \\
ERU & Emissions reduction unit \\
EU & European Union \\
EUA & EU allowance \\
EU ETS & EU Emissions Trading Scheme \\
HFC-23 & Fluoroform \\
JI & Joint Implementation \\
MR & Monitoring report \\
PDD & Project Design Document \\
UN & United Nations \\
UNFCC & United Nations Framework Convention on Climate Change \\
\hline
\end{tabular}




\section{B Emissions reductions via the Joint Implementation (JI) mech-}

\section{anism}

The guidelines for participation in the JI mechanism are described in UNFCCC (2006). Parties may apply to one of two different JI "tracks". The first track consists in a simplified procedure that allows the host party itself to verify that emissions reductions of a project are indeed "additional to any that would otherwise occur" and issue the correspondent amounts of ERUs. Under track 2, verification and issuance of ERUs has to follow the verification procedure under the JI supervisory Committee.

As in the CDM, the first step consists in project participants developing a project design document (PDD), which contains all the information specified in the JI guidelines. The PDD must show that the project has been approved by all the involved Parties, how the emission reductions are to be achieved, and that its baseline and monitoring plan is in line with the required criteria specified in JI guidelines. The PDD has to be submitted to an accredited independent entity (AIE), who makes the PDD publicly available for a 30-consultation period involving all relevant stakeholders. The AIE then determines whether the PDD provides all necessary information and makes its determination publicly available. If no review on the part of a Party involved in the project or the JISC is requested within 45 days, the PDD is "determined" to be final, which means that the project can be implemented. After implementation has started, project participants periodically have to submit a monitoring report about the achieved emissions reductions to an AIE (which is typically different to the AIE involved in the review of the PDD). The monitoring report is made publicly available, and the AIE has to verify the emission reductions. This verification report then is again made publicly available and declared final after 15 days, provided that no review on the part of a Party involved in the project or the JISC is requested. The last step consists in the issuance of Emissions Reduction Units (ERUs) according to the number of verified tons of $\mathrm{CO}_{2}$ during the monitoring period.

\section{Cointegration and error correction anaylsis}

This section provides some technical details for the cointegration and error correction analysis. As explained in a non-technical way in Section 3.2 , initially a long-run relationship is estimated. Thus, we estimate the following model using OLS: 


$$
C_{t}=\beta+\gamma P_{t}+u_{t}
$$

The estimated residuals $\hat{u}_{t}$ are used in the subsequent steps. A Phillips-Perron unit root test is used in order to test for a unit root in the estimated residuals. This procedure is commonly referred to as Engle-Granger single equation cointegration test. The error correction model we estimate is specified as follows:

$$
\Delta C_{t}=c \Delta P_{t}+\alpha \hat{u}_{t-1}+e_{t}
$$

Please note that data properties require modeling $e_{t}$ as a $\mathrm{GARCH}(1,1)$-process. This cointegration and error correction analysis is conducted using daily data; the price series are in logs. The sample period is Spring 2009 - Spring 2017. The sequences of adjustment speed parameters and p-values are then aggregated to the monthly frequency used in the remainder of the paper. 
Figure 7: Probability of nonbinding import limit and cointegration
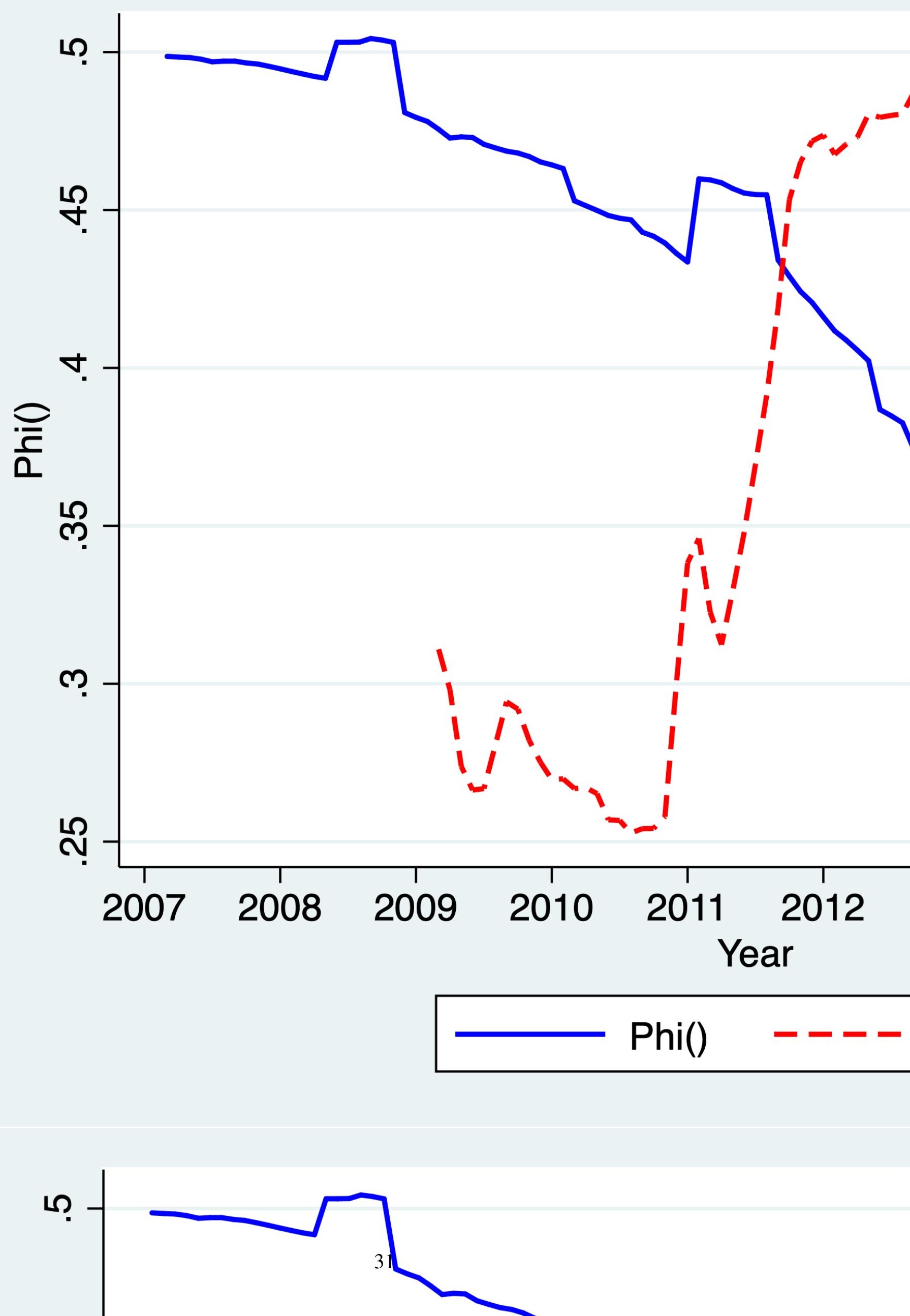
Figure A1: Prices for CERs and ERUs

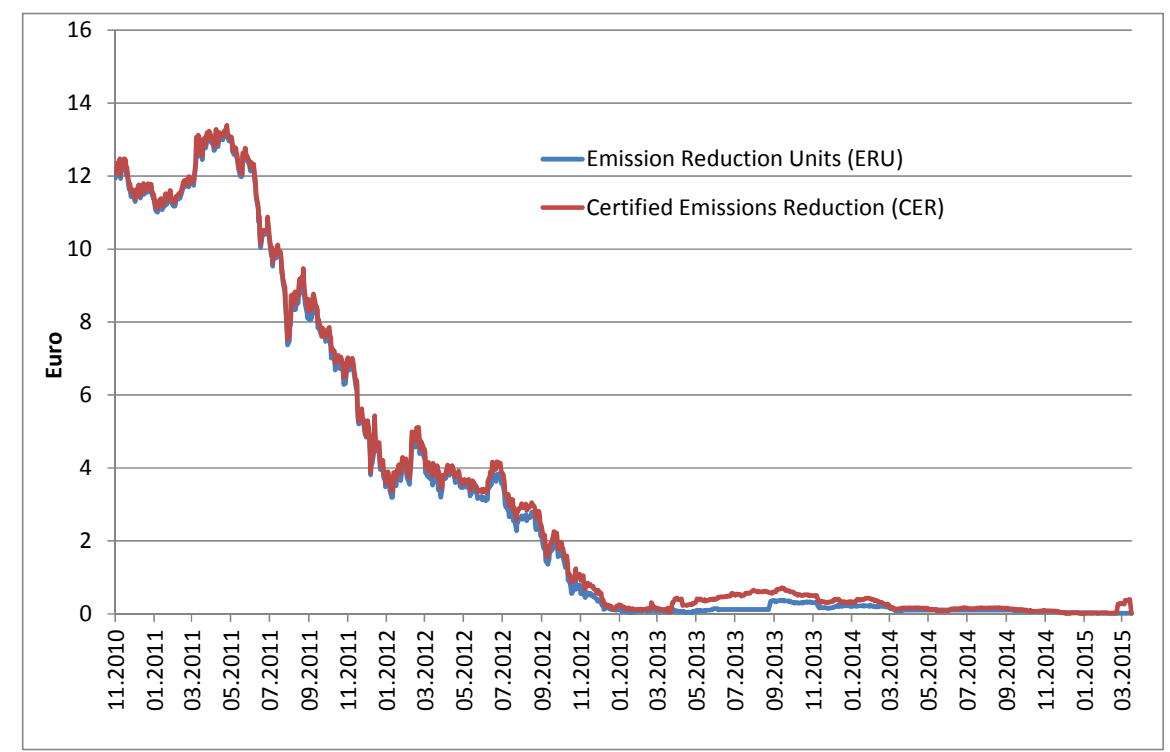

Source: 1-year futures from ICE, accessed via Thomson Reuters Eikon.

Figure A2: Average delay between start of comment period and registration, by month of registration

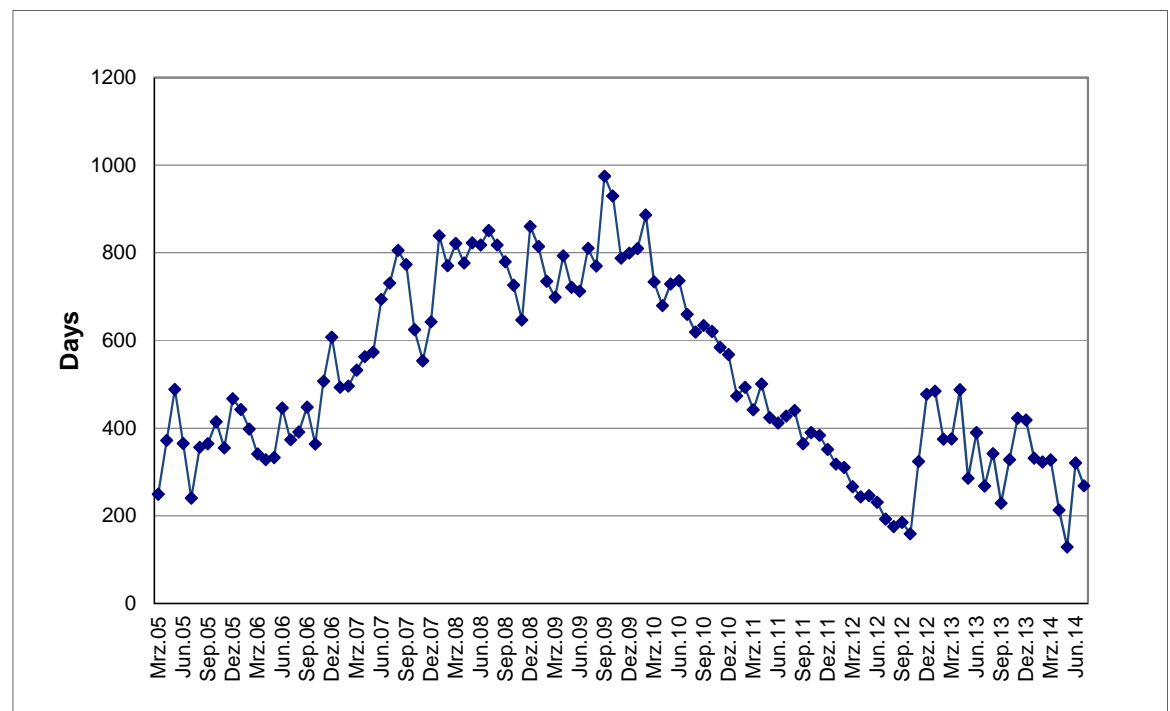

Source: CDM pipeline from December 2015, Graph 8. 
Figure A3: Average delay between MR and issuance, by month of issuance

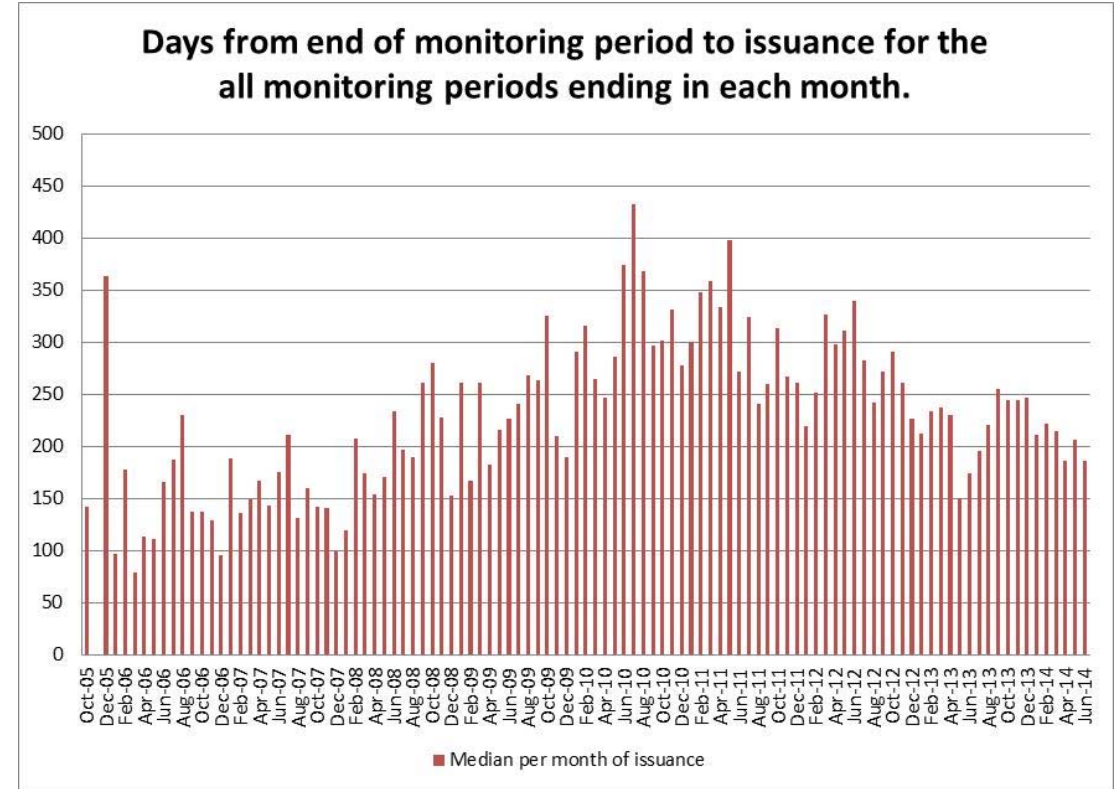

Source: CDM pipeline from December 2015, Graph 4.

Figure A4: Cumulative number of projects at different stages of the CDM cycle

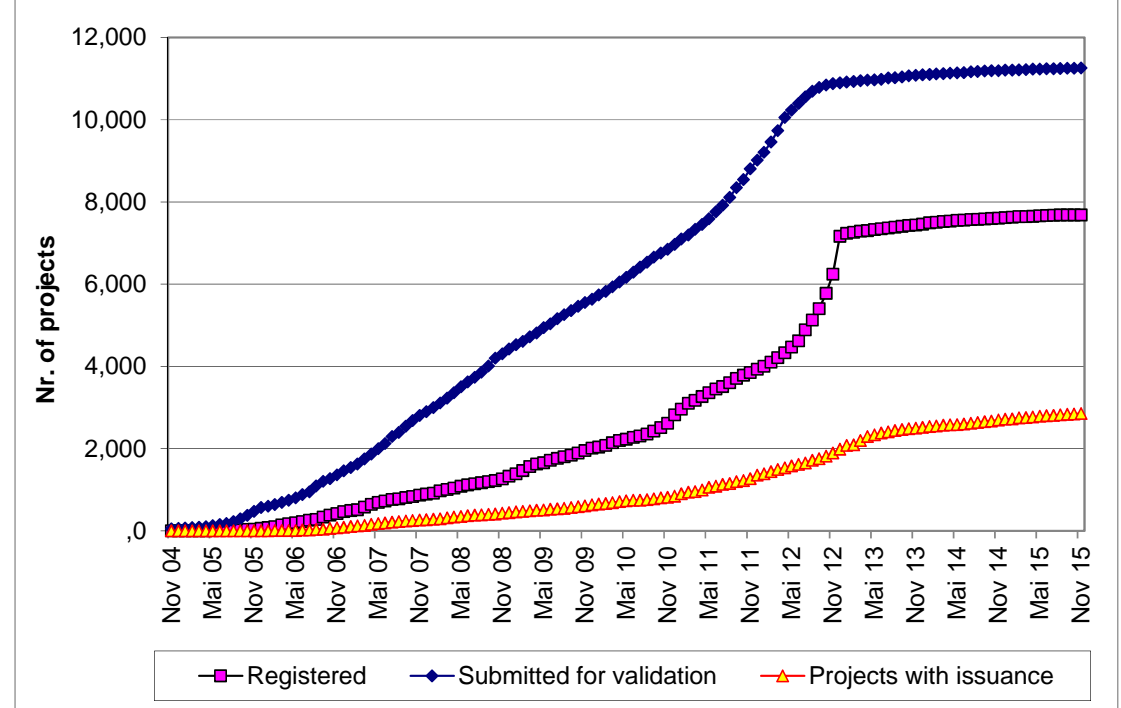

Source: United Nations, CDM pipeline from December 2015. 
Figure A5: Expected CERs by project type

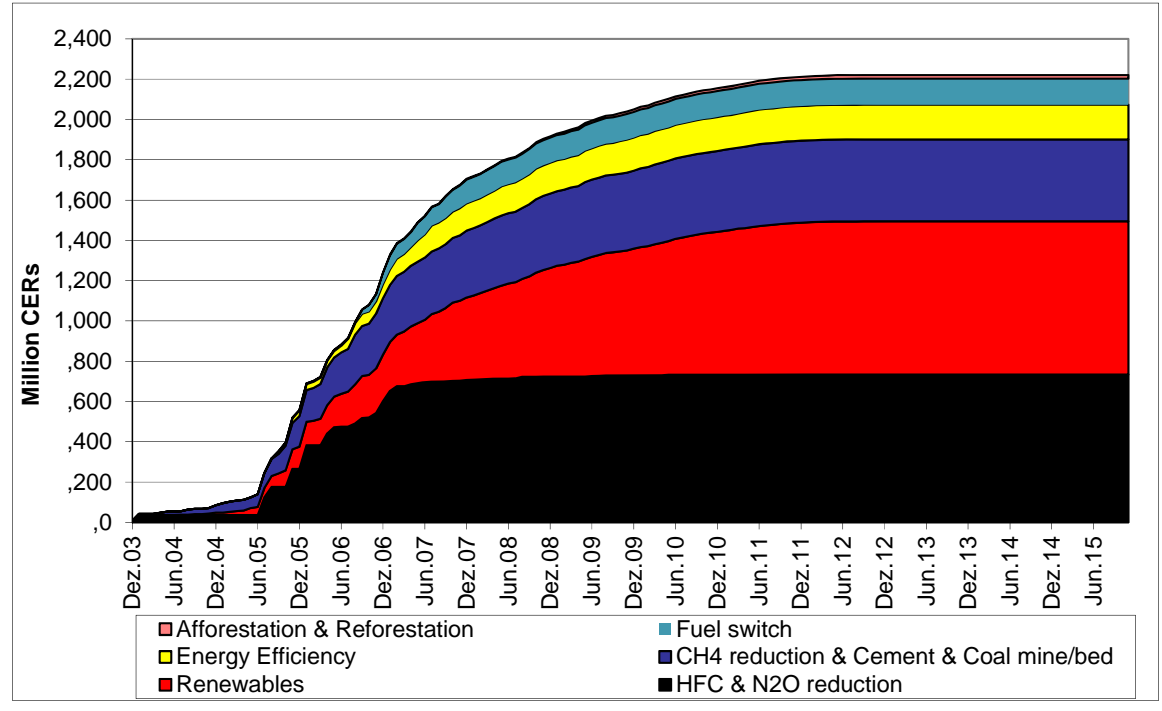

Source: CDM pipeline from December 2015, Chart 8. 